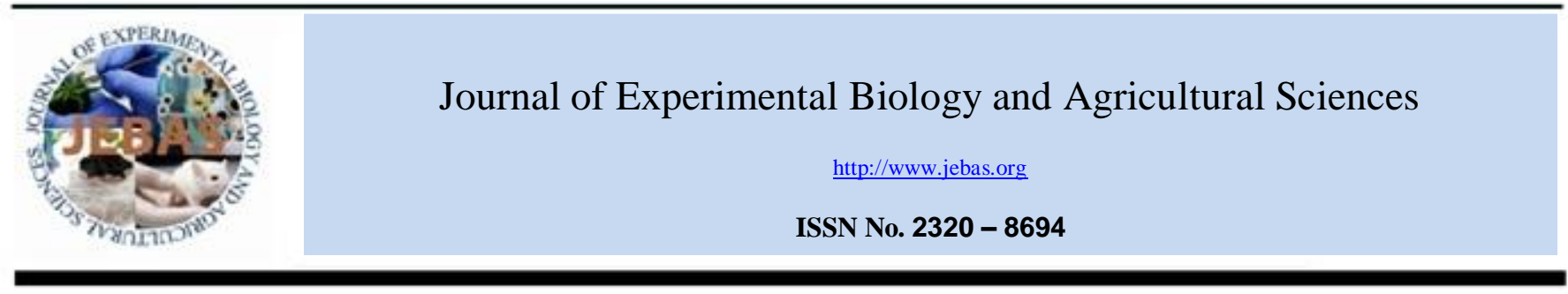

\title{
DEVELOPMENT OF IN VITRO SCREENING SYSTEM FOR FOOD HABIT RELATED RISK ANALYSIS
}

\section{Mandy Bruch* and Elmar Mohr}

University of Rostock, Faculty of Agricultural and Environmental Sciences, Chair of Animal Health and Animal Welfare, Justus-von-Liebig-Weg 6b, 18059 Rostock

Received - April 24, 2015; Revision - May 13, 2015; Accepted - August 31, 2015

Available Online - September 02, 2015

DOI: http://dx.doi.org/10.18006/2015.3(4).384.393

\begin{abstract}
KEYWORDS
Using chamber

IPEC-J2 cells

Porcine intestine

Papain

Risk assessment

ABSTRACT

In order to assess the health risk that associated with the consumption of unknown feed or food ingredients, there is a strong need of developing an in vitro screening system. The test system should be fast, reliable, inexpensive and without the necessity of performing animal tests. Furthermore, it should also provide important clues to the potential danger of unknown substances. The present study examines the extent to which cell and tissue cultures can be used for such studies. It should be ascertained whether the cell cultures can replace the native intestinal epithelium in terms of their sensitivity and provide accurate results as a quick "screening system". As a model for intestinal operations ex vivo tissue cultures from the native intestinal epithelium of the pig and the permanent cell line IPEC-J2 were used. The cell culture was characterized in terms of their morphological and functional properties (TEER, tight-junction proteins).Various studies (short-circuit measurements, translocation of $\left[{ }^{3} \mathrm{H}\right]-\mathrm{mannitol}$ ) were performed to IPEC-J2 cells and the native intestinal epithelium in order to compare the functional properties of both systems. Finally, the response of the addition of "unknown" test substances (papain and wheat extract) were investigated to determine whether the functional parameters of both systems are affected by these test substances or not. The IPEC-J2 cells show a more significant influence in their functionality by "unknown" substances than the control variant. Results of study revealed that the in vitro system reacts rapidly in response of unknown test substances and it is more sensitive. Therefore, it is possible to operate a "risk assessment" for "unknown" substances with the help of this developed screening system.
\end{abstract}

* Corresponding author

E-mail: mandy.bruch@uni-rostock.de (Mandy Bruch)

Peer review under responsibility of Journal of Experimental Biology and Agricultural Sciences.

Production and Hosting by Horizon Publisher (http://publisher.jebas.org/index.html).

All rights reserved.
All the article published by Journal of Experimental Biology and Agricultural Sciences is licensed under a Creative Commons Attribution-NonCommercial 4.0 International License Based on a work at www.jebas.org.

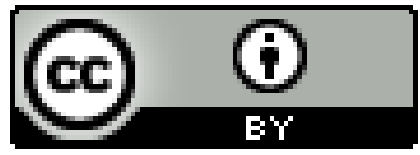




\section{Introduction}

Unknown ingredients of food and feed stuffs may pose a health risk for human and animal when consuming (Krul et al., 2000; Schmidt et al., 2011). Studies which should elucidate constructive the possible effect of these substances on an organism, often are based on animal experiments (Glaeser \& Fromm, 2008; Cehak et al., 2013; Yan et al., 2013). Feeding trials with genetically modified plants (Reuter \& Aulrich, 2003) or food additives (Lodemann et al., 2013) are expensive and potentially under ethically controversial agenda, because the animals are killed after food intake in order to examine the tissue and the blood. Problem related to the comparability of the results in potentially inhomogeneous test material like animals are also associated with these types of studied. For these reasons, it is feasible to support or partially replace these studies by in vitro systems? Cell and tissue cultures have long been used in medical and pharmaceutical research. Effect of drugs, macromolecules and other substances on cell absorption and transportation properties are already being studied in cell cultures (Artursson \& Karlsson, 1991; Uil et al., 1997; Neumann et al., 2004; Weng et al., 2005; Grunwald et al., 2006; Cardinali et al., 2013; Jarmolowska et al., 2013).

The intestinal epithelium has been used especially for the absorption of ions (Frömter \& Diamond, 1972; Frings et al., 1999), macromolecules (Warshaw et al., 1971; Bruch et al., 2008) and probiotics (Johnson et al., 2010; Lodemann et al., 2006). The ussing technique is an accepted procedure for the use of tissues and cell cultures for transport studies (Bajka et al., 2003; Rozehnal et al., 2012; Song et al., 2013). The native porcine intestinal epithelium is an established model for studies of the transport of ions and high molecular weight substances (Herrmann et al., 2012; Miyake et al., 2013). The permanent cell line IPEC-J2 is characterized and considered a suitable model for the jejunum of pig (Schierack et al., 2006; Mariani et al., 2009; Geens \& Niewold, 2011; Brosnahan \& Brown 2012). The combination of these already known methods of investigation can be used to estimate the possible occurring risk of an unknown substance. A rapid and easily performing screening system could be based on a cell or tissue culture giving first indications of a potential hazard. With the development of such an in vitro test system the normally required animal testing's could be reduced and complemented by a low-cost alternative method. The present study examined the extent to which appropriate cell and tissue cultures can be used for the detection of potentially hazardous substances.

Furthermore, suitable parameters in order to detect the effect of harmful substances in an in vitro system, reactivity of cell culture and ex vivo tissue cultures (native intestinal epithelium), differences in sensitivity between cell and tissueculture, suitability of cell and tissue-cultures, substance dependent differences between these two and the accuracy of cell culture screening system were also tested in the present study.

\section{Materials and Methods}

The studies used as a model for intestinal operations ex vivo tissue cultures of native intestinal epithelium of the pig (slaughterhouse material) and IPEC-J2 cell cultures. For these two systems morphological and functional parameters were determined before study. The morphological characteristics were studied by histological and intravital-microscopic analysis. Additionally the molecular biological detection of tight-junction proteins was occurred. The passive functional properties were characterized by the diffusion of tritiumlabeled Mannitol $\left(\mathrm{H}^{3}\right)$. As a measure of active transport properties of cell culture monolayers and the native epithelium, the response to the addition of sodium and the transport of essential amino acids was used (Rhoads et al. 1994; Zhang et al. 2014).

In order to investigate to extend at which these system have the ability to transporting gradients with high molecular mass, GFP (green fluorescent protein) was used (Bruch et al. 2008). Papain and wheat extract, which consisted of the variety Greina, in the wild-type variant (isogenic) and in the genetically modified variant (transgenic) were used to determine the effect of an "unknown" substance on the above parameters. The statistical analysis was performed using Excel 2010 and Sigma Plot $11^{\text {th }}$. Statistical analysis of data was carried out using standard analysis of variance. The significance was determined using the F-test, least significant difference (LSD) was computed at the 5\% probability level. Significant differences have been represented by different letters.

\subsection{Native epithelium}

The native epithelium (tissue culture) was recovered from the ileum of pigs of the breed German Landrace (male, castrated, age on average 180 days). After commercial slaughter, the tissue was removed, placed in ice-cold buffer containing indomethacin $(2.8 \mathrm{nM})$ and gassed with carbogen (a mixture of $5 \%$ carbon gas and $95 \%$ oxygen gas). This part of the gut was chosen because of the occurrence of jejunal transporters in the ileum as well as M-cells mediated transport mechanisms in Peyer's patches.

\subsection{Cell line and Culture Conditions}

To compare the results obtained by native epithelium to cell line, commercially available IPI-21 cells from the ileum of the pig would be the best choice. Unfortunately, they do not grow on transwell-plates so transport studies in Ussing chamber experiments are not possible. To work around this problem IPEC-J2 cells were used. The IPEC-J2 cell line is a nontransformed intestinal cell line originally derived from jejunal epithelia isolated from a neonatal, unsuckled piglet and maintained as a continuous culture (Berschneider, 1989). Cells were purchased from FLI (Federal Research Institute for Animal Health, Germany). Unless otherwise indicated, cells 
were cultured on Dulbecco's modified eagle medium (DMEM)/HAM's F-12 (1:1) supplemented with 10\% fetal calf serum (Biochrom, Germany) and maintained in an atmosphere of $5 \% \mathrm{CO}_{2}$ at $37^{\circ} \mathrm{C}$. Cells reached confluence after 3-4 days and were cultivated on polyester membranes with $0.4 \mu \mathrm{m}$ pore size (Corning Costar). The investigations were carried out in the period of 6-8 days after sowing (Schierack et al., 2006), in a passage of 20-40.

\subsection{Morphological Characterization}

The IPEC-J2 cells were stained immunohistochemically after 3 days growth on "cover slips". The cell nucleus, F-actin and tubulin structures of the cells were stained with antibodies (Dapi, Bodipy and anti-tubulin, Sigma Aldrich, Germany) and fluorescent secondary antibodies (Alexa 594, Sigma Aldrich, Germany). Immunofluorescence microscopy was performed with a Zeiss LSM 510 META confocal laser scanning microscope (CLSM, Zeiss, Germany)

\subsection{Functional parameters}

\subsubsection{Transepithelial electrical resistance (TEER)}

The cells were cultured as described above and seeded with a density of $6 * 10^{5}$ cells $/ \mathrm{cm}^{2}$. Transwell filters or snapwell filter made by polycarbonate with $0.4 \mu \mathrm{m}$ pore size (Corning, The Netherlands) was used for this culturing. The TEER was measured daily with a volt-ohm-meter (WPI, Germany). The transepithelial resistance of the native epithelium was determined during the Ussing chamber experiments.

\subsubsection{Ussing chamber experiments}

The retrieved samples of intestine were prepared by removing the muscularis and serosa and fixed in Ussing chambers (Scientific Instruments, Germany) with an area of $1 \mathrm{~cm}^{2}$. On both sides, $5 \mathrm{ml}$ buffer $(115 \mathrm{mM} \mathrm{NaCl} ; 25 \mathrm{mM} \mathrm{NaHCO}$; 0,4 $\mathrm{mM} \mathrm{NaH} \mathrm{PO}_{4} ; 2,4 \mathrm{mM} \mathrm{Na}_{2} \mathrm{HPO}_{4} ; 5 \mathrm{mM} \mathrm{KCl}, 5 \mathrm{mM}$ glucose; $1,2 \mathrm{mM} \mathrm{CaCl} 2 ; 1,2 \mathrm{mM} \mathrm{MgCl} 2$ add $1,4 \mu \mathrm{M}$ Indomethacin, pH7.4) was added. The chambers were gassed with carbogen at a temperature of $37^{\circ} \mathrm{C}$. The initial resistance of the epithelium was in the range of 90-150 $\Omega$. Confluent cell culture monolayers on snapwell filters have been investigated in Ussing chambers under the same conditions described above. During the experiments, test substances were added to the mucosal or serosal side of the Ussing chamber.

\subsubsection{Short circuit $\left(\mathrm{I}_{\mathrm{sc}}\right)$ measurements}

As a functional parameter the current after mucosal addition of $\mathrm{NaCl}(115 \mathrm{mmol})$ was used. After an equilibration period of 15 min (constant value of $\mathrm{I}_{\mathrm{sc}}$ ) $\mathrm{NaCl}$ was added and the reaction of tissue or cell culture monolayer in the absence or presence of the test substance was registered. After completion of the experiment, Theophylline $\left(10^{-2} \mathrm{~mol}^{*} \mathrm{l}^{-1}\right)$ was added to prove the viability. Only in case of a reaction to Theophylline data were used for further investigation.

\subsubsection{Diffusion of $\left[{ }^{3} \mathrm{H}\right]$-mannitol}

Tightness of tissue or monolayer was investigated with tritiumlabeled mannitol (11.7 Ci/mM, conc. $3.85 * 10^{-6} \mathrm{mM}$, Amersham, Great Britian). It added to the mucosal side of native epithelium and cell culture in the Ussing chamber. Hourly a sample from the serosal compartment was taken. The samples were analyzed by liquid scintillations chromatography (Liquid Scintillation Analyser, Tri-Carb 2900TR, Perkin Elmer, USA) and the diffusion in relation to the initial amount of $\left[{ }^{3} \mathrm{H}\right]$ mannitol was calculated in $\% / \mathrm{h} * \mathrm{~cm}^{2}$ or as standard permeability coefficient (Papp).

\subsubsection{Transport of essential amino acids}

The tritium-labeled amino acids methionine, leucine, lysine and tyrosine were added to the mucosal side of the Ussing chamber $\left(79.7 \mathrm{Ci} / \mathrm{mM}, 0.57 * 10^{-6} \mathrm{mM}\right)$. Hourly a sample was taken from the serosal side of the Ussing chamber. The samples were analyzed by liquid scintillations chromatography (Liquid Scintillation Analyser, Tri-Carb 2900TR, Perkin Elmer, USA) and the transportin relation to the initial amount of $\left[{ }^{3} \mathrm{H}\right]$-amino acids was calculated in $\% / \mathrm{h} * \mathrm{~cm}^{2}$.

\subsubsection{Transport of high molecular weight substances}

To investigate a potentially available transport of high molecular substances, in buffer dissolved GFP (green fluorescent protein, about $4 \mathrm{mg} / \mathrm{ml}$ contain in genetically modified tobacco plants) was added to the mucosal side of the native epithelium or the IPEC-J2 cells. Hourly a sample was taken from the serosal side of the Ussing chamber. The samples were analysed by ELISA (sandwich-ELISA, Bioserv $\mathrm{GmbH}$, Germany) and the transport/diffusion in relation to the initial amount of GFP was calculated in $\% / \mathrm{h} * \mathrm{~cm}^{2}$.

\subsubsection{Effect of complex test substances}

As a model for the effect of ,unknown" complex test substances on cell function, papain and wheat extract were selected. Papain (Sigma Aldrich, Germany) is a proteolytic enzyme from papaya. It serves the plant to repel insects and affects the fibrin structures (Wittmack \& Tomaschek 1978, Konno \& Barber 2014). In addition, it is considered to be allergenic and therefore it was added in the concentration of 1 $\mathrm{mg} / \mathrm{ml}$ to the mucosal side of the native epithelium or to mucosal and serosal side of the cell monolayer.

Wheat extract containing gluten, known to be an agent responsible for potential incompatibilities (Smecuol et al., 1999; Menard et al. 2012) was chosen as an additional test substance. A solution prepared from wheat grains of the variety Greina (isogene (wild type variant) and transgenic (genetically modified) variant), conc. $1 \mathrm{mg} / \mathrm{ml}$ buffer, was added to the mucosal side of the native epithelium and the IPEC-J2 cells. 


\section{Results}

\subsection{Morphological characterization}

Results demonstrated by Figure. 1 and proofed by the occurrence of Occludin (Figure. 2), IPEC-J2 cells formed a dense monolayer with formation of tight-junctions. The TEER ranged between $4000-4500 \Omega / \mathrm{cm}^{2}$ on day 7 of cultivation. The standard permeability coefficient (Papp) of $\left[{ }^{3} \mathrm{H}\right]$-mannitol was 1.3386E-06 on IPEC-J2 monolayer and 3.572-E-07 on native epithelium at a resistance of $110 \Omega$ (Figure. 3).

\subsection{Functional characterization}

To characterize electrophysiological properties the response to addition of sodium was examined. Both the IPEC-J2 cells, as well as the native epithelium showed an increase in shortcircuit current $\mathrm{I}_{\mathrm{sc}}$ : about $16 \mu \mathrm{A} / \mathrm{cm}^{2}$ in cell culture monolayer and about $7 \mu \mathrm{A} / \mathrm{cm}^{2}$ in native epithelium (Figure. 4).

\subsection{Measurement of amino acid transport}

Both in native epithelium and IPEC-J2 monolayer a transport of the amino acids leucine, lysine, methionine and tyrosine was measured. The transport rates for the native epithelium have been 0.007 (Lys), 0.013 (Met), 0.017 (Leu), 0.024 (Tyr)

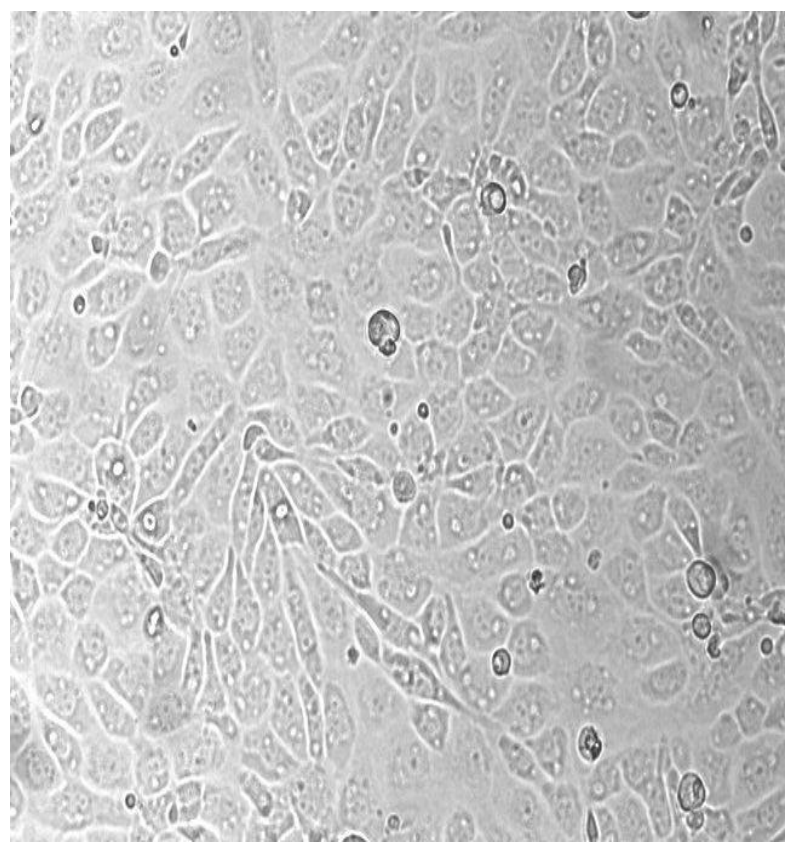

Figure 1 IPEC-J2 cells, 7 days cultured on polycarbonate membrane $\mathrm{pmol} / \mathrm{s}^{*} \mathrm{~cm}^{2}$ and for the IPEC-J2 cells are 37.80 (Met), 58.56 (Leu), 41.55 (Lys), 104.13 (Tyr) $\mathrm{pmol} / \mathrm{s}^{*} \mathrm{~cm}^{2}$ (Figure. 5).

3.4 Transport of high molecular substances

To investigate the occurrence of unspecific transport mechanisms for high molecular substances (e.g. ABCtransporter), GFP was used. A transport of a high molecular substance such as GFP could be detected. In native intestinal epithelium a transport of GFP of $0.133 \% / \mathrm{h}^{*} \mathrm{~cm}^{2}$ of the initial concentration was measurable, in the IPEC-J2 monolayer the transport of GFP was only $0.0306 \% / \mathrm{h}^{*} \mathrm{~cm}^{2}$ (Figure. 6).

3.5 Influencing the morphological and electrophysiological parameters by complex test substances

\subsubsection{Papain}

An influence on the functional and morphological parameters of the test systems, by papain is detectable especially on IPECJ2 monolayer. Native epithelium did not response to papain given on the mucosal side. In contrast, IPEC-J2 monolayers are affected in most cases, only by papain donation to the serosal side. Figure 7 shows the influence of serosal addition of papain to the IPEC-J2 monolayers. It is visible already after 2 hours and further strengthened over the test period. In the same way lysine transport is affected (Figure. 8).

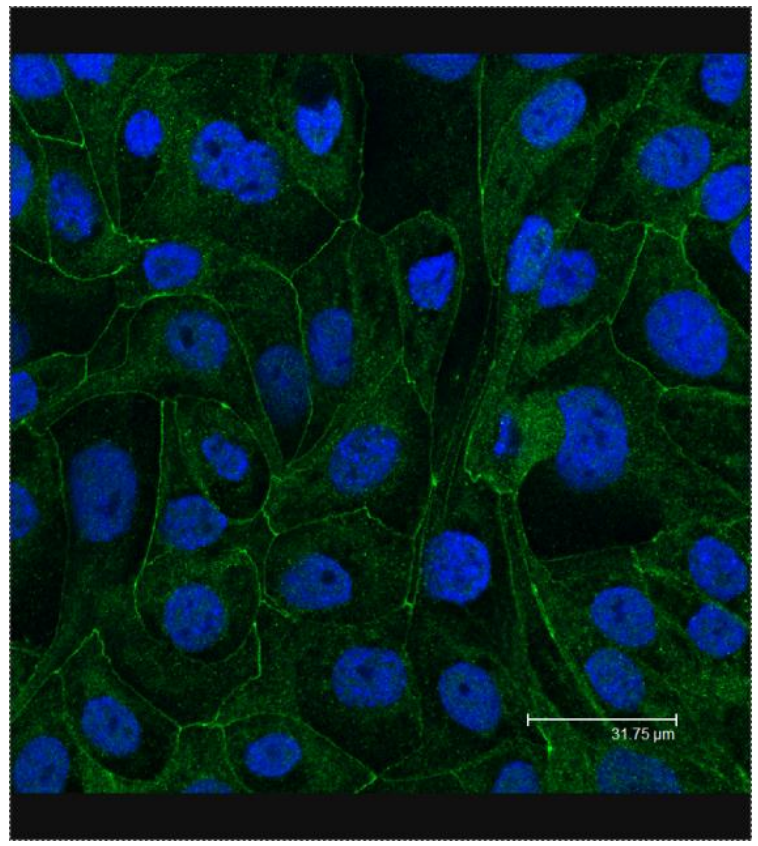

Figure 2 IPEC-J2 cells, nucleus (blue, Dapi) and Occludin (green, Alexa 488) 


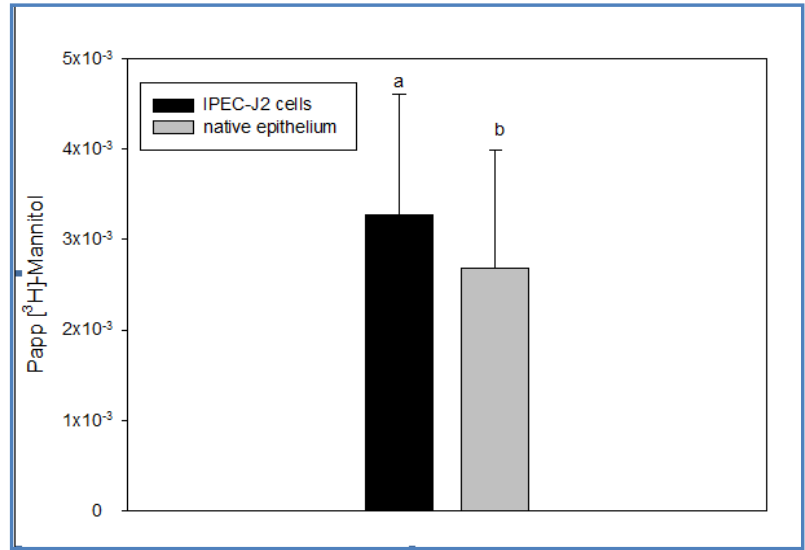

Figure 3 standard permeability coefficient (Papp) of $\left[{ }^{3} \mathrm{H}\right]-$ mannitol on native intestinal epithelium and on IPEC-J2monolayer $(n=8)$. Values fallowed by the same letter are not significantly different at 5\% DMRT.

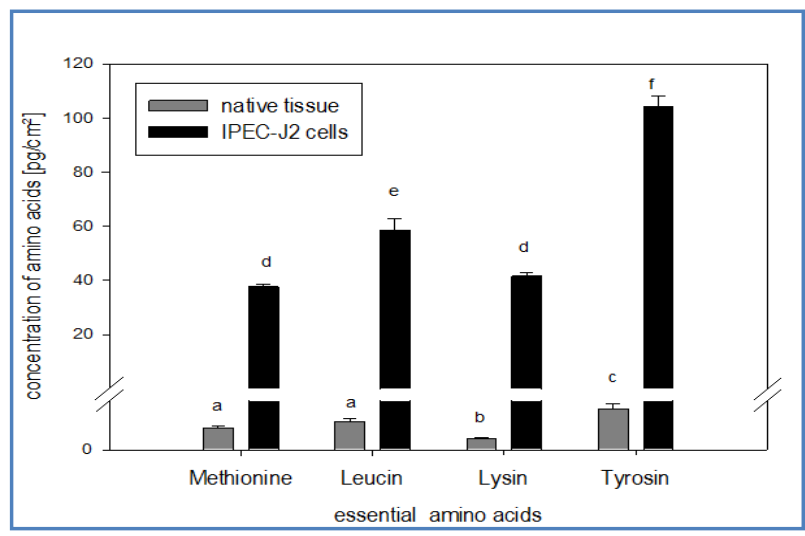

Figure 5 Transport of amino acids (methionine, leucine, lysine, tyrosine) by IPEC-J2 cells and native tissue (Ileum, $\mathrm{n}=10$ ). Values fallowed by the same letter are not significantly different at 5\% DMRT.

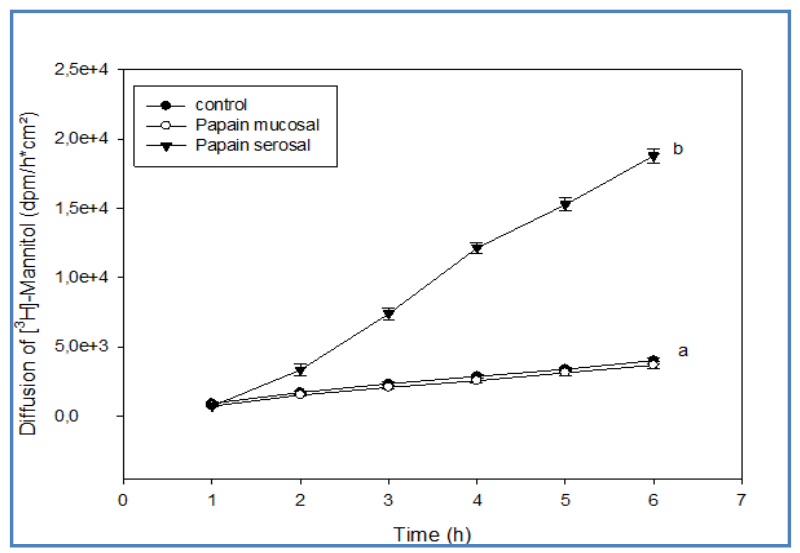

Figure 7 Diffusion of $\left[{ }^{3} \mathrm{H}\right]$-mannitol by IPEC-J2 monolayer and native epithelium after mucosal addition of papain $(n=8)$.Values fallowed by the same letter are not significantly different at 5\% DMRT.

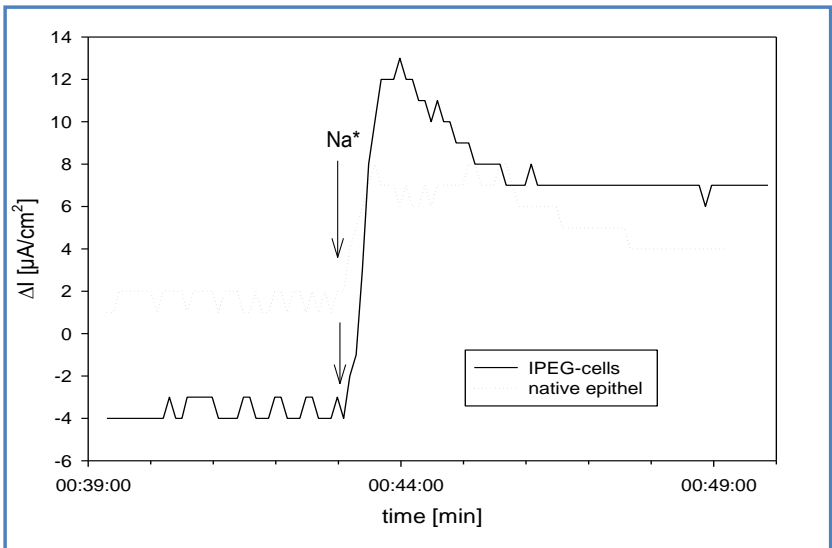

Figure 4 short circuit current $\left(\mathrm{I}_{\mathrm{sc}}\right)$ after the addition of sodium on the apical side of IPEC-J2 cells and native epithelium $(n=8)$.

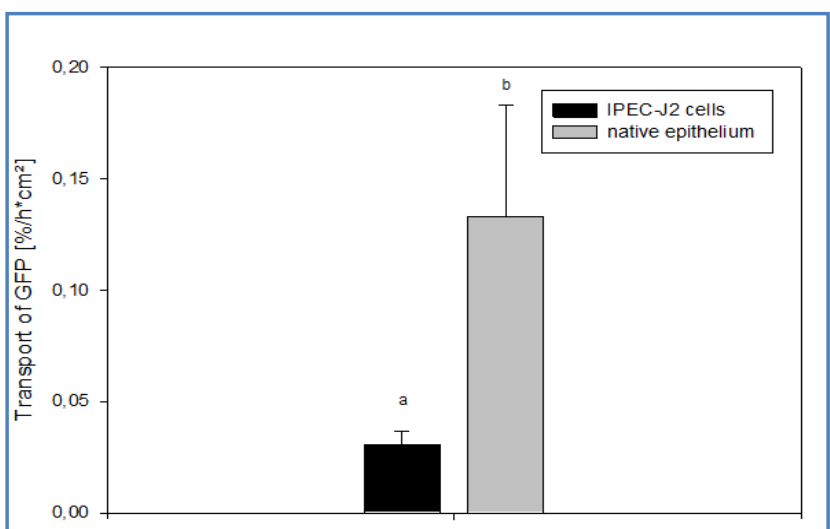

Figure 6 Transport of intact GFP (green fluorescent protein) by IPEC-J2 cells and native tissue $(n=8)$. Values fallowed by the same letter are not significantly different at $5 \%$ DMRT.

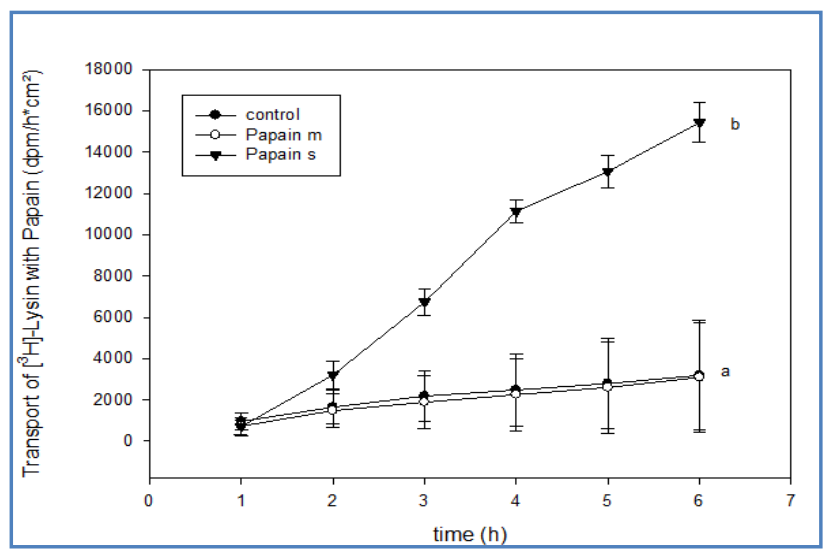

Figure 8 Influence of mucosal or serosal addition of papain on the translocation of lysine on the IPEC-J2 monolayer $(n=8)$ during 6 hours.Values fallowed by the same letter are not significantly different at 5\% DMRT. 
Furthermore no reaction was reported on the mucosal addition and a significant increase in the presence of papain on the serosal side. An effect of papain is also detectable in the measurement of short circuit current caused by sodium. The sodium-induced $\mathrm{I}_{\mathrm{sc}}$ in IPEC-J2 monolayer is $4 \mu \mathrm{A} / \mathrm{cm}^{2}$ and was significantly reduced by the addition of papain (Figure. 9). Interestingly, there is no significant difference in the reaction between additions of papain to the mucosal orserosalside. The $\mathrm{I}_{\mathrm{sc}}$ was always reduced by about $5 \mu \mathrm{A} / \mathrm{cm}^{2}$ compared to the control.

\subsubsection{Wheat extract}

Presence of wheat gluten with the resultant potential incompatibilities (Smecuol et al., 1999; Menard et al., 2012) could have an influence on cellular transport mechanisms. In addition, because wheat was available as isogenic and transgenic version, the possible influence of non-identical genetic material was of some interest and studied in this experiment. To evaluate the potential influence on lysine transport of IPEC-J2 cells wheat extract was admit to the mucosal side. The lysine transport showed a significant increase compared to the control variant without wheat extract (Figure. 10)

There were no significant differences between the different wheat varieties. The diffusion of $\left[{ }^{3} \mathrm{H}\right]$-mannitol am IPEC-J2monolayer increased significantly after mucosal addition (Figure.11). In contrast, a similar effect in native epithelium could not be observed. In the next step, the influence of wheat extract on the sodium-induced short circuit current $\left(\mathrm{I}_{\mathrm{sc}}\right)$ was investigated. The results indicate a possible influence of $\mathrm{I}_{\mathrm{sc}}$ by wheat extract: the addition of isogenic and transgenic wheat extract was made to the mucosal side. The $I_{s c}$ increased immediately and was significantly higher than in the control variant over the entire time course (Figure. 12).

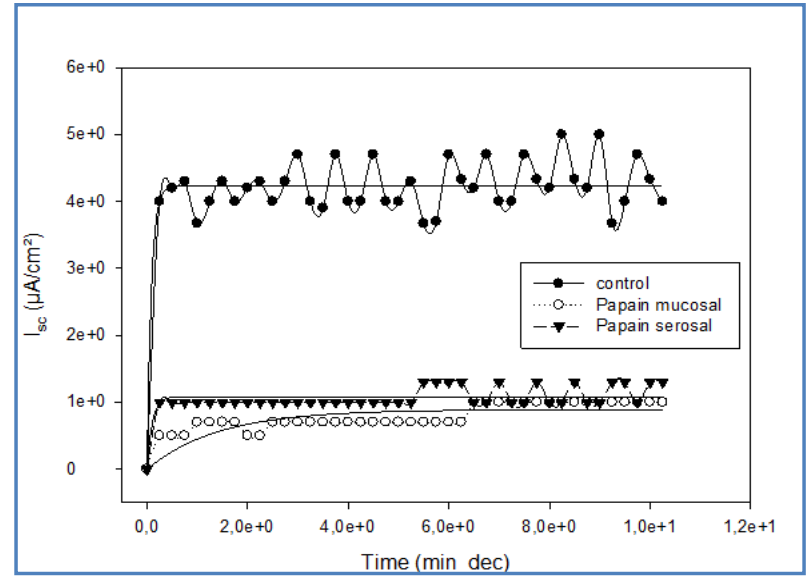

Figure 9 short circuit current $\left(\mathrm{I}_{\mathrm{sc}}\right)$ after the addition of sodium on the apical side of IPEC-J2 cells under the influence of mucosal or serosal addition of papain (curve fit by Sigma Plot 11.0).

\section{Discussion and conclusion}

\subsection{Morphological and functional characterization}

The IPEC-J2 cells are capable due their origin to serves as a model for the porcine intestine. Due the high compliance of height, weight, anatomy and physiology of the gastrointestinal tract of pigs and humans (Wernersson et al., 2005), this model seems also to be suitable for human (Schierack et al., 2006, Brosnahan et al., 2012). This hypothesis is strengthened by the observation of tight junctions in cells like it is detectable in human beings. The measured TEER values are consistent with the data from literature (Schierack et al., 2006). Furthermore, the diffusion of $\left[{ }^{3} \mathrm{H}\right]$-mannitol under control conditions in IPEC-J2 monolayer compared to the native intestinal epithelium is not significantly different. This result indicates that a dense intact epithelium was formed. From these facts it was derive that this in vitro system is morphologically comparable with other described in vitro systems (Geens \& Niewold, 2011).

In the reaction of cells and native epithelium to the addition of sodium a significantly higher change in the short circuit current $\left(I_{s c}\right)$ in the cell culture was reported. This effect can be explained by the higher resistance of the complete intestine. There are several cell layers are present, causing an overall higher resistance. This shows that the cell culture system should be preferred when investigating the influence on sodium dependent transport processes. In the study of the transport of essential amino acids in the native epithelium and the IPEC-J2 monolayer a significant difference in the rate of transport was observed by various researchers (Rhoads et al., 1994; Zhang et al. 2014). The measured rate of transportation of amino acids methionine, tyrosine, lysine and leucine is in IPEC-J2 cells was reported significantly higher than in native porcine intestine.

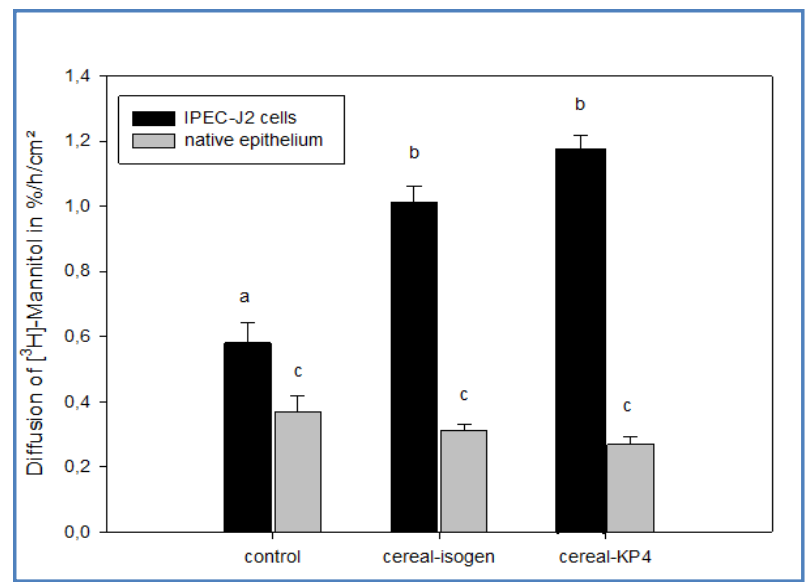

Figure 10 Diffusion of $\left[{ }^{3} \mathrm{H}\right]$-mannitol by IPEC-J2 monolayer and native epithelium after addition of wheat extract $(n=8$, isogen (cereal-isogen) and transgenic (cerea-KP4). Values fallowed by the same letter are not significantly different at $5 \%$ DMRT. 


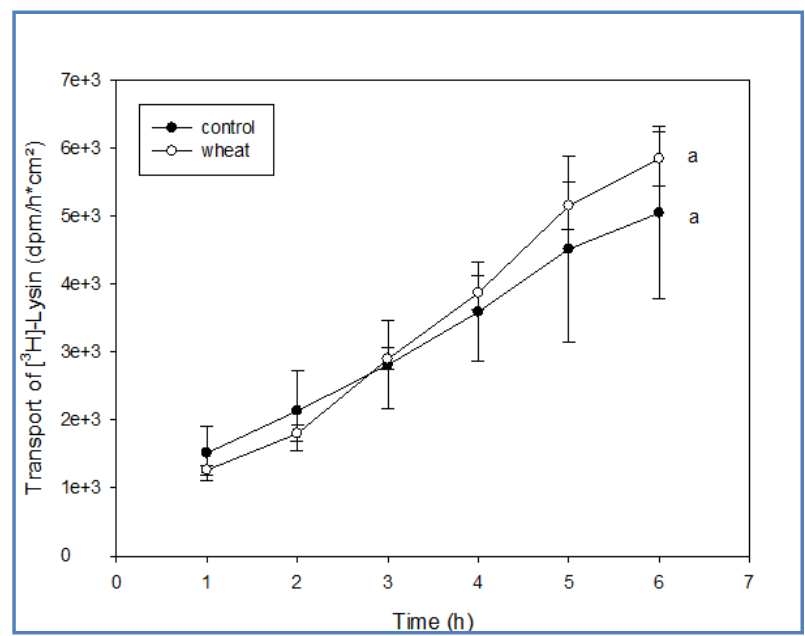

Figure 11 Translocation of $\left[{ }^{3} \mathrm{H}\right]$-lysine on the IPEC-J2 monolayer $(n=8)$ by addition of wheat extract during 6 hours.

Values fallowed by the same letter are not significantly different at 5\% DMRT.

Investigations with the aid of IPEC-J2 cells are able to show the transport of these essential amino acids faster and more effectively than it can be done using native epithelium.

In contrast, in the study about transport of high molecular substances, e.g. GFP, a significantly higher transport by the native intestinal epithelium can be detected. Cell culture systems therefore, appear to be less suitable for studies about the absorption and transport of high molecular substances. Possibly, the mechanisms responsible for the transport of high molecular substances are formed only to a very limited extent in cell culture monolayers. In intestinal transport other cell types, such as M-cells may be involved, which may be present only in the native epithelium of the intestine. This observation confirms the tests described in the literature, for example, that Caco-2 cells alone are not in a position to carry GFP (Heppner et al., 2001). Therefore it is recommended to investigate the transport of high molecular substances only in native epithelium, especially when transport routes are not yet known.

\subsection{Use of in vitro systems for risk assessment}

The suitability of the in vitro system for a risk assessment was checked using the enzyme papain and an unknown mixture of wheat extract. Papain is a protein-splitting enzyme and it serves insects repellent and affects the fibrin structures (Wittmack \& Tomaschek 1978; Huby et al., 2000; Konno \& Barber, 2014). The applied wheat extract was a sample from genetically modified wheat, the potential ability to influence physiological processes in the gastrointestinal tract should be investigated. Due to the higher sensitivity of cell cultures, the reaction of these is faster and more sensitive as the ex-vivo systems to a possible influence of paracellular transport routes. As the results show in figure 5 , the influence of the diffusion of

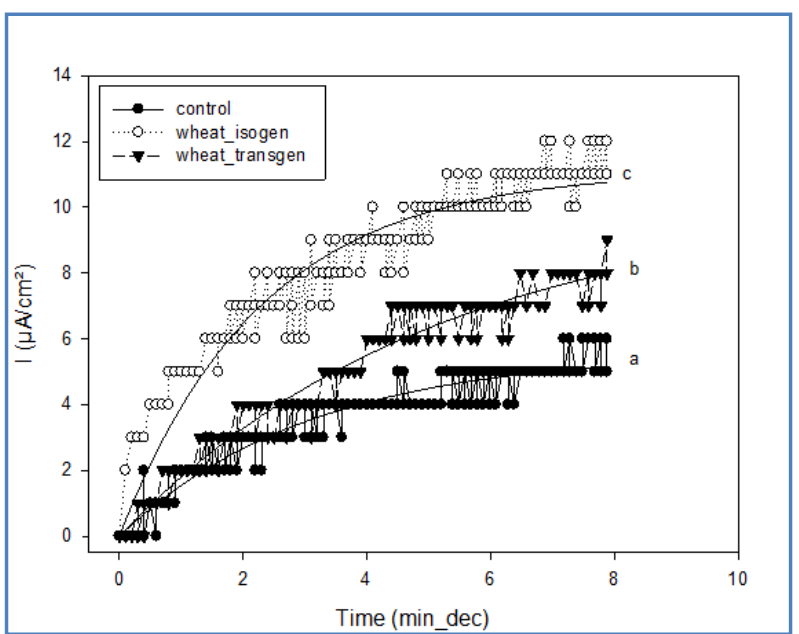

Figure 12 short circuit current $\left(\mathrm{I}_{\mathrm{sc}}\right)$ after the addition of sodium on the apical side of IPEC-J2 cells under the influence of addition of wheat extract (isogenic or transgenic, curve fit by Sigma Plot 11.0).Values fallowed by the same letter are not significantly different at 5\% DMRT.

$\left[{ }^{3} \mathrm{H}\right]$-mannitol under test conditions, such the addition of papain (Figure. 8) and „wheat“(Figure. 10) is significantly more pronounced in cell cultures.

\subsection{Response to the addition of papain}

Both the diffusion of $\left[{ }^{3} \mathrm{H}\right]$-mannitol, the sodium -induced $\mathrm{I}_{\mathrm{sc}}$ and the transfer of the amino acid lysine influenced by the addition of papain. However, this effect could be detected only in serosal addition to the native intestinal epithelium and on the cell monolayer. The increased diffusion of mannitol on IPEC$\mathrm{J} 2$ monolayer in serosal addition of papain indicates a possible change in terms of diffusion properties and in the integrity of the monolayer. May be the damage of the epithelium on the basolateral side by the addition of papain is the trigger for the significantly higher mannitolflux. Papain also showed an effect on the transport of lysine. Again, mucosal addition did not significantly influence the transport of the amino acid. Butif added serosal, the transport of lysine was significantly higher. Probably proteolysis action of the enzyme causes possibly a damaging effect on the basolateral side of the monolayer. Because no blocker experiments were performed, it could not be distinguished between an increase in transport and/or diffusion. By the addition of papain the $\mathrm{Na}-\mathrm{I}_{\mathrm{sc}}$ is significantly reduced. The cell monolayer has been no longer able to respond appropriately to the addition of sodium. Interestingly, this effect occurs in serosal and in mucosal addition of papain. Possibly, the epithelium was damaged or the electrophysiological properties were affected by the addition of papain. This will be investigated in further studies.

4.4 Response to the addition of wheat extract 
In addition, wheat extract was used as a test substance. The diffusion of mannitol was significantly increased by mucosal addition to the IPEC-J2 monolayer. Also the transport of lysine exhibits an increase under the influence of wheat extract. The $\mathrm{Na}-\mathrm{I}_{\mathrm{sc}}$ was also affected by the addition of wheat extract. Serosal addition of wheat extract was omitted because the test system was mainly developed to simulate the processes in the intact intestine. One possible explanation for the effect of wheat extract on mucosal addition to the cell culture might be bases on the effect of the wheat ingredients, because they contained gluten, which has an effect on the tight junction proteins (Smecuol et al., 1999).

Based on the response of the two test systems on the various test substances a stronger influence always shown on the morphological and functional properties of the cells culture monolayer compared to the control variant (complete ex vivo portion of the porcine intestine). The constant resistance of IPEC-J2 cells and the native epithelium during the experiment proof the stability of both test systems. The significantly higher response in the cell monolayer is therefore no artifact but inherent to the system.

The in vitro system reacts sensitively to any test substances. The observed changes in diffusion of mannitol, as wells as the electrophysiological $\left(\mathrm{Na}-\mathrm{I}_{\mathrm{sc}}\right)$ and transport properties (transport of lysine) are due to the influence of unknown components. In a risk assessment setup, the presented test systems should be implemented because the observed different responses make it possible to characterize the various possible influences of morphological and functional properties by the addition of various test substances.

Test systems that are based on in vitro experiments, are an effective alternative to animal experiments. The existing technical possibilities should be used to develop further in vitro test systems and apply this. The higher the accuracy and comparability with in vivo data, the number of applications would be developed. Research should invest in in-vitro systems to replace animal tests largely.

\section{Acknowledgment}

The authors thank Angelika Hauth for her excellent technical assistance.

\section{Conflict of interest}

Authors would hereby like to declare that there is no conflict of interests that could possibly arise.

\section{References}

Artursson P, Karlsson J (1991) Correlation between oral drug absorption in humans and apparent drug permeability coefficients in human intestinal epithelial (Caco-2) cells. Biochemical and Biophysical Research
Communications 175:880-885. 291X(91)91647-U.

Bajka BH, Gillespie CM, Steeb CB, Read LC, Howarth GS (2003) Applicability of the using chamber technique to permeability determinations in functionally distinct regions of the gastrointestinal tract in the rat. Scandinavian Journal of Gastroenterology 38:732-741. DOI: 10.1080/00365520310003101.

Berschneider HM (1989) Development of normal cultured small intestinal epithelial cell lines which transport $\mathrm{Na}$ and $\mathrm{Cl}$ (Abstract). Gasteroenterology 69:A41.

Brosnahan AJ, Brown DR (2012) Porcine IPEC-J2 intestinal epithelial cells in microbiological investigations. Veterinary Microbiology 156:229-237. DOI:10.1016/j.vetmic.2011.10.017.

Bruch M, Kacholdt K, Ott EM, Zeyner A, Mohr E (2008) The effect of glibenclamide on GFP-transport at the porcine small intestine. Journal of Physiology and Biochemistry 64:342.

Cardinali A, Rotondo F, Minervini F, Linsalata V, D'Antuono I, Debellis L, Ferruzzi MG (2013) Assessement of verbascoside absorption in human colonic tissue using the Ussing chamber model. Food Research International 54:132138. DOI: 10.1016/j.foodres.2013.06.017.

Cehak A, Schroeder B, Feige K, Breves G (2013) In vitro studies on intestinal peptide transport in horses. Journal of Animal science 91:5220-5228, DOI: 10.2527/jas.2013-6325.

Frings M, Schultheiß G, Diener M (1999) Electrogenic $\mathrm{Ca}^{2+}$ entry in the rat colonic epithelium. Pfluegers ArchiveEuropean Journal of Physiology 439:39-48. DOI: $10.1007 / \mathrm{s} 004249900159$.

Frömter E, Diamond J (1972) Route of passive ion permeation in epithelia. Nature New Biology 235:9-13.

Geens MM, Niewold TA (2011) Optimizing culture conditions of a porcine epithelial cell line IPEC-J2 trough a histological and physiological characterization. Cytotechology 63:415-423. DOI: $10.1007 / \mathrm{s} 10616-011-9362-9$

Glaeser H, Fromm MF (2008) animal models and intestinal drug transport. Expert Opinion on Drug Metabolim and Toxicology 4:347-361, DOI: 10.1517/17425255.4.4.347.

Grunwald S, Krause R, Bruch M, Henle T, Brandsch M (2006) Transepithelial flux of early and advanced glycation compounds across caco- 2 cell monolayers and their interaction with intestinal amino acid and peptide transport systems. British Journal of Nutrition 95:1221-1228, DOI: 10.1079/BJN20061793. 
Heppner FL, Christ AD, Klein MA, Prinz M, Fried M, Kraenhenbuhl JP, Aguzzi A (2001) Transepithelial prion transport by $M$ cells. Nature Medicine 7:976-977. DOI: 10.1038/nm0901-976.

Herrmann J, Schröder B, Klinger S, Thorenz A, Werner AC, Abel H, Breves G (2012) Segmental diversity of electrogenic glucose transport characteristics in the small intestines of weaned pigs. Comparative Biochemistry and Physiology Part A: Molecular \& Integrative Physiology 163:161-169. doi:10.1016/j.cbpa.2012.05.204.

Huby RDJ, Dearman RJ, Kimber I (2000) Why are some proteins allergens? Toxicology Sciences 55:235-246.

Jarmolowska B, Teodorowicz M, Fiedorowicz E, SienkiewiczSzalpka E, Matysiewicz M, Kostyra E (2013) Glucose and calcium ions may modulate the efficiency of bovine $\beta$ casomorphin-7 permeability trough a monolayer of caco-2 cells. Peptides 49:59-67. DOI: 10.1016/j.peptides.2013.08.017.

Johnson AM, Kaushik RS, Hardwidge PR (2010) Disruption of transepithelial resistance by enterotoxicgenic Escherichia coli. Veterinary Microbiology 141:115-119. DOI: 10.1016/j.vetmic.2009.08.020

Konno H, Barber GN (2014) The sting controlled cytosolicDNA activated innate immune pathway and microbial disease. Microbes and Infection 16:998-1001. DOI: 10.1016/j.micinf.2014.10.002.

Krul C, Luiten-Schuite A, Baan R, Verhagen H, Mohn G, Feron V, Havenaar R (2000) Application of a dynamic in vitro gastrointestinal tract model to study the availability of food mutagens, using heterocyclic aromatic amines as model compounds. Food and Chemical Toxicology 38:783-792, DOI: 10.1016/S0278-6915(00)00071-5.

Lodemann U, Huebener K, Jansen N, Martens H (2006) Effects of Enterococcus faecium NCIMB 10415 as probiotic supplement on intestinal transport and barrier function of piglets. Archives of Animal Nutrition 60:35-48, DOI: 10.1080/17450390500468099.

Lodemann U, Dillenseger A, Aschenbach JR, Martens $\mathrm{H}$ (2013) Effects of age and controlled oral dosing of Enterococcus faecium on epithelial properties in the piglet small intestine. Beneficial Microbes 4:335-344, DOI: 10.3920/BM2013.0004.

Mariani V, Palermo S, Fiorentini S, Lanubile A, Giuffra E (2009) Gene expression study of two widely used pig intestinal epithelial cell lines: IPEC-J2 and IPI-2I. Veterinary Immunology and Immunopathology 131:278-284, DOI: 10.1016/j.vetimm.2009.04.006.

Menard S, Lebreton C, Schumann M, Matysiak-Budnik T, Dugave C, Bouhnik Y, Malamut G, Cellier C, Allez
M, Crenn P, Schulzke JD, Cerf-Bensussan N, Heyman M (2012) Paracellular versus transcellular intestinal permeability to gliadin peptides in active celiac disease. American Journal of Pathology 180:608-615, DOI: 10.1016/j.ajpath.2011.10.019.

Miyake M, Toguchi H, Nishibayashi T, Higaki K, Sugita A, Koganei K, Kamada N, Kitazume MT, Hisamatsu T, Sato T, Okamoto S, Kanai T, Hibi T (2013) Establishment of novel prediction system of intestinal absorption in humans using human intestinal tissues. Journal of Pharmaceutical Sciences 102:2564-2571, DOI: 10.1002/jps.23609.

Neumann J, Bruch M, Gebauer S, Brandsch M (2004) Transport of the phosphonodipeptide alafosfalin by the $\mathrm{H}^{+}$/peptide cotransporters PEPT1 and PEPT2 in intestinal and renal epithelial cells. European Journal of Biochemistry 271:2012-2017. DOI: 10.1111/j.1432-1033.2004.04114.x.

Reuter T, Aulrich K (2003) Investigations on genetically modified maize (Bt-maize) in pig nutrition: fate of feedingested foreign DNA in pig bodies. European Food Research Technology 216:185-192, DOI: 10.1007/s00217-002-0642-7 .

Rhoads JM, Chen W, Chu P, Berschneider HM, Argenzio RA, Paradiso AM (1994) L-Glutamine and L-asparagine stimulate $\mathrm{Na}+\mathrm{H}+$ exchange in porcine jejuna enterocytes. American Journal of Physiology - Gastrointestinal and Liver Physiology 266:G828-G838.

Rozehnal V, Nakai D, Hoepner U, Fischer T, Kamiyama E, Takahashi M, Yasuda S, Mueller J (2012) Human small intestinal and colonic tissue mounted in the ussing chamber as a tool for characterizing the intestinal absorption of drugs. European Journal of Pharmaceutical Sciences 46:367-373. DOI: 10.1016/j.ejps.2012.02.025.

Schierack P, Nordhoff M, Pollmann M, Weyrauch KD, Amasheh S, Lodemann U, Jores J, Tachu B, Kleta S, Blikslager A, Tedin K, Wieler LH (2006) Characterization of a porcine intestinal epithelial cell line for in vitro studies of microbial pathogenesis in swine. Histochemistry and Cell Biology 125:293-305. DOI: 10.1007/s004818-005-0067-z.

Schmidt K, Höflich C, Bruch M, Entzian K, Horn P, Kacholdt A, Kragl U, Leinweber P, Mikschofsky H, Mönkemeyer W, Mohr E, Neubauer K, Schlichting A, Schmidtke J, Steinmann A, Struzyna-Schulze C, Wilhelm R, Zeyner A, Ziegler A, Broer I (2011) BioOK - A comprehensive system for analysis and risk assessment of genetically modified plants. Journal für Kulturpflanzen, 63:232-248,

Smecuol E, Vazquez H, Sugai E, Niveloni S, Pedreira S, Cabanne A, Fiorini A, Kogan Z, Mauriño E, Meddings J, Bai JC (1999) Sugar tests detect celiac disease among firstdegree relatives. American Journal of Gastroenterology 94:3547-3552. DOI: 10.1016/S0002-9270(99)00704-2. 
Song D, Guo J, Han F, Zhang W, Wang Y, Wang Y (2013) Establishment of an in vitro model of the human placental barrier by placenta slice culture and using chamber. Bioscience Biotechnology Biochemistry 77:1030-1034, DOI: 10.1271/bbb.120976.

Uil JJ, Van Elburg RM, Van Overbeek FM, Mulder CC, Vanberge-Henegouwen GP, Heymany HAS (1997) Clinical implications of the sugar absorption test: Intestinal permeability test to assess barrier function. Scandinavian Journal of Gastroenterology, Supplement, 32:70-80.

Warshaw AL, Walker WA, Cornell R, Isselbacher KJ (1971) Small intestinal permeability to macromolecules. Transmission of Horseradish peroxidase into mesenteric lymph and portal blood. Laboratory Investigation 25:675-684.

Weng XH, Beyenbach KW, Quaroni A (2005) Cultured monolayers of the dog jejunum with the structural and functional properties resembling the normal epithelium. American Journal of Physiology - Gastrointestinal and Liver Physiology 288:G705-G717. DOI: 10.1152/ajpgi.00518.2003.
Wernersson R, Schierup MH, Jørgensen FG, Gorodkin J, Panitz F, Stærfeldt HH, Christensen OF, Mailund T, Hornshøj H, Klein A, Wang J, Liu B, Hu S, Dong W, Li W, Wong GKS, Yu J, Wang J, Bendixen C, Fredholm M, Brunak S, Yang H, Bolund L (2005) Pigs in sequence space: A $0.66 \mathrm{X}$ coverage pig genome survey based on shotgun sequencing. BMC Genomics 6:7p.

Wittmack L, Tomaschek A (1978) Die mikroskopische Untersuchung der Getreidemehle. Zeitschrift für Analytische Chemie 22:279, DOI: 10.1007/BF01338118.

Yan S, Sun F, Li Z, Xiang J, Ding Y, Lu Z, Tian Y, Chen H, Zhang J, Wang Y, Song P, Zhou L, Zheng S (2013) Reduction of intestinal electrogenic glucose absorption after duodenojejunal bybass in a mouse model. Obesity surgery 23:1361-1369. DOI: 10.1007/s11695-013-0954-7.

Zhang S, Ren M, Zeng X, He P, Ma X, Qiao S (2014) Leucine stimulates ASCT2 amino acid transporter expression in porcine jejuna epithelial cell line (IPEC-J2) trough PI3K/Akt/m TOR and ERK signaling pathways. Amino acids, DOI: 10.1007/s00726-014-1809-9. 